\title{
HISTORIA, NACIONALISMO Y DISCRIMINACIÓN EN LAS ESCUELAS DE LA FRONTERA NORTE DE CHILE*
}

\author{
HISTORY, NATIONALISM, AND DISCRIMINATION IN THE SCHOOLS \\ OF THE NORTHERN BORDER OF CHILE
}

\author{
Carlos Mondaca-Rojas ${ }^{* *}$, Pamela Zapata-Sepúlveda ${ }^{* * *}$ y Wilson Muñoz-Henríquez****
}

\begin{abstract}
El artículo analiza la presencia diacrónica de componentes nacionalistas en el sistema educativo de la frontera norte de Chile desde la instalación del Estado chileno en estos territorios post-Guerra del Pacífico hasta nuestros días. Desde una perspectiva cualitativa se presenta un ejercicio metodológico que incluye el uso de fuentes documentales del período conocido como de chilenización y la observación etnográfica en contextos de aula contemporáneos (observaciones, entrevistas grupales, e individuales en profundidad), demostrando que el nacionalismo está presente en nuestra educación nacional y que aún utiliza una lógica asimilacionista que facilita la reproducción de formas de discriminación de tipo nacionalista, racial y étnica.
\end{abstract}

Palabras claves: Educación, migración, nacionalismo, discriminación, frontera, interculturalidad.

The article analyzes the diachronic presence of nationalist components in the educational system of the northern border of Chile since the installation of the Chilean State in these post-Pacific War territories until current times. From a qualitative perspective, a methodological exercise is presented that includes the use of documentary sources from the period known as Chileanization and ethnographic observation in contemporary classroom contexts (observations, group interviews, and in-depth individual interviews). This demonstrates that nationalism is present in our national education and still uses an assimilationist logic that facilitates the reproduction of forms of discrimination of a nationalistic, racial, and ethnic type.

Key words: Education, migration, nationalism, discrimination, border, interculturality.

\section{Introducción}

La migración posee una larga tradición en la frontera norte de Chile (Tapia y González, 2014; Contreras, Tapia y Liberona, 2017). Este espacio fronterizo se caracteriza por albergar importantes flujos de movilidad con los países vecinos de Perú y Bolivia (Stefoni, 2003; 2004), posibilitando importantes procesos de intercambio económico, político y sociocultural (Guizardi y Garcés, 2013; Guizardi 2014; Rojas y Vicuña 2014; Vicuña y Rojas 2015; Dilla y Álvarez, 2018). El fenómeno se ha visto potenciado por las nuevas dinámicas migratorias que han incorporado un creciente número de estudiantes provenientes de otros países en el sistema educativo. Esto ha generado un escenario intercultural emergente que plantea importantes desafíos a toda la comunidad educativa, tanto a nivel regional como nacional (Zapata, et al., 2015; Mondaca, 2018).
En este complejo escenario se espera que el sistema educativo debiese poseer las herramientas que logren la inclusión de estudiantes de orígenes y características diversas y la generación de ciudadanos interculturales acordes con esta realidad (Poblete, 2009). El reconocimiento oficial del Ministerio de Educación respecto del ingreso, permanencia y ejercicio de los derechos de los estudiantes hijos de inmigrantes en establecimientos educacionales, ya es una realidad en los colegios y escuelas de la región. No obstante, existen importantes limitantes históricas y nacionalistas que impiden llevar a cabo esta integración de manera inclusiva e intercultural (Pavez y Galaz, 2018).

Al respecto, Mondaca y Gajardo (2013) sostienen que lo que caracterizaría al sistema educativo regional es que aun en la actualidad se aplica un currículum de tipo hegemónico, nacionalista, y que utiliza a la educación intercultural bilingüe (EIB) como la única forma de contacto con la diversidad

\footnotetext{
* Artículo resultado de los Proyectos Fondecyt Nº 1191317 y 1181713, además de proyecto UTA Mayor 5724-19.

** Universidad de Tarapacá. Académico Departamento de Educación. Correo electrónico: cemondacar@uta.cl

*** Universidad de Tarapacá. Académica Departamento de Psicología y Filosofía. Correo electrónico: pzapatas@ uta.cl

*****Universidad de Tarapacá. Investigador Asociado Departamento de Educación. Correo electrónico: wilsonsocio@gmail.com
} 
cultural, aludiendo exclusivamente a lo indígena. Así, se prestaría poca atención a las necesidades de aprendizajes de los estudiantes de colectivos diversos desde el currículum y desde las prácticas docentes, excluyendo a estudiantes de otras latitudes o culturalmente distintos. Incluso los programas que atienden la diversidad como la educación intercultural bilingüe, más bien tienden a reforzar la asimilación que a reconfigurar esta estructura (Mondaca y Gajardo, 2013; Mondaca, Gajardo y Sánchez, 2014).

Estos hallazgos regionales se enmarcan dentro de una producción científica reciente que ha tematizado la relación entre la migración y el sistema educativo en Chile, centradas principalmente en las diferenciaciones que existen entre estudiantes chilenos e inmigrantes de la Región Metropolitana del país (Tijoux, 2013; Joiko y Vásquez, 2016). En general, la evidencia en el norte también muestra que las escuelas no incorporarían formalmente la atención de colectivos vulnerables de migrantes (Mondaca, 2018). De manera que si bien las normativas y los discursos facilitan la incorporación de los hijos de inmigrantes a los establecimientos educativos chilenos (siguiendo la Declaración Universal de los Derechos Humanos), en la práctica este derecho se ha visto denegado y postergado, pues hay evidencia de discriminación y segregación de estudiantes inmigrantes debido a que los procesos de integración utilizados son de tipo asimilacionista del acervo cultural chileno (Mardones, 2006; Mondaca, 2018).

Nuestro trabajo se inserta dentro de esta línea de investigación, donde el objetivo es demostrar la presencia de elementos nacionalistas en las escuelas en la frontera norte de Chile desde tiempos de la incorporación de estos territorios a la soberanía nacional en tiempos de postguerra del Pacífico y del período conocido como de chilenización, que estamparon en el transcurso del tiempo la presencia de una escuela homogeneizadora de la nación chilena en la frontera norte.

Como se observa en el artículo, a partir de fuentes documentales se muestra cómo las prácticas educativas nacionalistas del pasado pervivieron en el tiempo hasta la actualidad; al revisar las prácticas de aula contemporáneas podemos observar que en la vida cotidiana escolar de niños y niñas hijos de inmigrantes peruanos y bolivianos en las escuelas y colegios de Arica, aún subsisten estas prácticas asimilacionistas.
Nuestra hipótesis de trabajo sostiene que este componente nacionalista se ha impuesto desde el periodo de soberanía chilena en la frontera norte y preexiste hasta nuestros días en el sistema escolar. Esto dificultaría los procesos de integración y promovería prácticas discriminatorias de tipo nacionalista, racial y étnica.

Para comprender la naturaleza de nuestro objeto de estudio utilizamos un enfoque cualitativo por medio de un ejercicio metodológico que intenta, basados en una estrategia multimétodo, unir el pasado histórico con el presente a partir de la pervivencia de una ideología nacionalista en nuestro sistema educativo regional y nacional.

En primer lugar, se presenta un análisis documental con el objetivo de entregar un marco histórico que permite contextualizar y comprender las raíces históricas del fenómeno estudiado. Para esta primera estrategia se analizaron documentos oficiales de los Fondos de la Intendencia de Tacna, la Gobernación de Arica y la Subdelegación de Putre, donde se obtuvo información valiosa referida al periodo histórico conocido como de chilenización (1883-1929) y su influencia en el sistema escolar regional. Estos documentos provienen principalmente del Archivo Vicente Dagnino ubicado en la Biblioteca Central de la Universidad de Tarapacá (Arica, Chile).

En segundo lugar se exponen los principales resultados del trabajo de campo realizado en escuelas y colegios, urbanos y rurales, de Arica, donde se administraron tres técnicas de recolección de información: 36 entrevistas grupales a estudiantes de $7^{\circ}$ y $8^{\circ}$ año de enseñanza primaria; 45 observaciones en salas de clases y en recreo de cursos de $4^{\circ}$ a $8^{\circ}$ año; y 16 entrevistas a informantes clave como profesores y otros actores adultos del sistema escolar. De esta segunda fase se obtuvo un cuerpo de datos de 3.500 unidades textuales de análisis y 188 categorías jerárquicas de análisis. Luego de realizar la triangulación y un primer análisis de toda la información tanto histórica como etnográfica con el programa NVivo, se obtuvieron las categorías codificadas y un mapa conceptual emergente.

Esto facilitó el análisis posterior, el que nos permitió conocer las experiencias cotidianas de niños y niñas hijos de inmigrantes en su proceso de incorporación y adaptación de las escuelas y colegios estudiados, considerando los procesos de enseñanza-aprendizajes asociados y los antecedentes históricos que han condicionado esta situación. 


\section{Estado, nación y escuela chilenizadora}

En el actual territorio de la región de Arica y Parinacota, la concepción de nación y la identidad nacionalista chilena es el resultado de una historia particular. La movilidad de distintos grupos humanos que caracterizaba a esta zona desde épocas prehispánicas y luego coloniales, fue duramente trastocada a fines del siglo XIX por la imposición de fronteras políticas. Esta fue una de las manifestaciones concretas de las políticas implementadas con la instauración de las repúblicas en Latinoamérica, las que apoyaron proyectos soberanos fundamentados en la adquisición de ciudadanías diferenciadas en los diversos países de América del sur. En nuestro caso concreto, y especialmente después de acaecido el conflicto bélico con Perú y Bolivia denominado Guerra del Pacífico (1879-1883), el Estado nacionalista chileno implantó un discurso de homogeneidad nacional en los nuevos territorios conquistados en la zona norte. Esto se manifestó en la invisibilización de la alteridad de una forma sistemática, negando la existencia de otras propuestas políticas ciudadanas y étnicas diferentes o contrarias a la historia nacional. De esta forma, se fueron poniendo límites y fronteras políticas e ideológicas, basadas en la racialización y contrarias al planteamiento de otras formas de discursos nacionalistas ajenos al proyecto modernizador.

La chilenización fue un proyecto político y étnico-identitario que se instauró sobre la base de la construcción de un relato historiográfico basado en lecturas nacionalistas militares chilenas, como por ejemplo la existencia y accionar de las Ligas Patrióticas Chilenas que promovían el nacionalismo (González, 2004), la expulsión sistemática de ciudadanos peruanos de la zona, la imposición sistemática de patrones culturales del centro-sur del país ${ }^{1}$, y la puesta en marcha de una política de nacionalización de las escuelas estatales. Este condicionamiento promovió la exaltación del civismo patrio, la aplicación de un ordenamiento jurídico nuevo, la instauración de un aparataje burocrático y militar jerárquico, y la implementación de un sistema nacional de escuelas (Aguirre y Mondaca, 2011).

Amparados en esta nueva maquinaria, el Estado chileno promulgó la constitución de un ente autónomo en la zona, respecto de otros Estados nacionales (particularmente Perú y Bolivia) y apoyó la creación de un concepto de Estado-nación como forma de pertenencia y lealtad colectiva (Mondaca, Rivera y
Aguirre, 2013). En este nuevo contexto, el Estado se mostró implacable con aquellas manifestaciones socioculturales que dieran muestra de contravenir su proyecto chilenizador en las escuelas, de forma general, en el área se procura suprimir la simbología cívica peruana y boliviana con acciones específicas, como evitar el izamiento de la bandera de estos países, mientras se promueve el uso de emblemas chilenos en todas las reparticiones públicas, escuelas y residencias. Sin embargo, esta disposición se ve contrariada paradójicamente por situaciones como la acaecida en Tacna el 14 de septiembre de 1892, cuando la Intendencia informa que "carece de una bandera nacional para enarbolar en su edificio en los días festivos y en los que naciones enemigas conmemoran algún acontecimiento político"2. Estos hechos serán una preocupación considerable a fines del siglo XIX. De hecho, en esta misma ciudad, el 27 de noviembre de 1899, se comunicó al Ministro de Instrucción Pública que:
$\mathrm{Al}$ acercarse las festividades de patrias de setiembre último se procuró que en todos los establecimientos públicos i en el domicilio de los compatriotas se izara la bandera nacional para no verlas en tan corto número comparadas con las que elevan los peruanos, el día 28 de julio, por concesión que ha recabado generalmente de Santiago $^{3}$.

Según los datos disponibles, para aquella época la mayoría de las escuelas públicas eran dirigidas por peruanos y no poseían banderas chilenas, lo que era importante para inculcar el sentimiento nacionalista, como se aprecia en la siguiente cita:

Si siempre es provechoso que los educandos reconozcan esa insignia patriótica, aquí es indispensable, por las razones que no se escaparon a UD, aparte de la designada por el hecho de que todos los colegios i escuelas peruanas los poseen de ricas telas i valiosas que procuran exhibir con hiriente empeño. Así no encontrará exagerado que solicite (\$50.-) para cada escuela de los consultados en el nuevo presupuesto, tanto de este departamento como del de Arica ${ }^{4}$.

Se resuelve entonces mandar a confeccionar banderas chilenas y "dotar a cada escuela de un 
estandarte con los colores nacionales para que los alumnos carguen en cada formación o festividad escolar" . Para 1901 cada escuela pública contará ya con astas para izar las mencionadas banderas ${ }^{6}$. Además, se incorporó en los establecimientos educativos la entonación "de los himnos de Yungay y el nacional, el uso de textos escolares aprobados por el gobierno y el cierre y prohibición de escuelas clandestinas" 7 .

En este contexto, la escuela se convierte en una preocupación temprana para los habitantes del Norte Grande. Por ejemplo, en la localidad de Putre, el 30 de septiembre de 1905, el juez de distrito, Mauricio Reinand, le informaba al Gobernador Departamental de Arica lo siguiente:

\begin{abstract}
Rogando a Us, disculpe mi carta, me permito pedirle tome nota de ella: recabando de su buena administración la creación de una escuela para varón que sea chilena, y que no se entreguen los niños de este pueblo a manos de quienes harían de ellos unos enemigos de las ideas que Us. representa en este departamento ${ }^{8}$.
\end{abstract}

Como se puede observar, pasados más de 15 años de posesión de estos territorios nortinos por las tropas y administración chilena, el problema de la instauración de la educación resulta compleja, pues existe una resistencia simbólica que fomenta el nacionalismo peruano, dando cuenta del ambiente sociopolítico del momento. Esto queda en evidencia cuando en 1916 se advierte que los directores de escuelas de Tacna y Arica, Pedro Espina y Ester Silva, "propenden a la difusión del sentimiento nacional en ese Departamento"'. Esto ocurre en los recintos educativos tanto rurales como urbanos, promoviendo, según señala otro documento, la "enseñanza ligada a la nacionalidad, con el fin de poder arraigar el tan anhelado valor patrio" 10 .

Un importante hito en la construcción del civismo patrio chilenizador ocurrió luego de la aprobación en 1920 de la Ley de Educación Primaria Obligatoria (LIPO) ${ }^{11}$. Esta permitió, desde el aparato educacional, vigilar y supervisar por medio de visitas el "Culto a los Emblemas Patrios en las Escuelas de la Provincia"12. En su marco se llagaron incluso a autorizar viajes de estudiantes a lugares donde ocurrieron eventos bélicos de importancia nacional, como ocurrió con una comisión de estudiantes de la Escuela
Superior de Niños $\mathrm{N}^{\circ} 1$ de Arica, la que llevó a la Escuela de Dolores (Pisagua):

Un álbum de fotografías de Arica, numerosos mensajes de los niños i dos coronas que serán depositadas en el monumento a Prat de Iquique i en la cripta de Dolores respectivamente. Todo con el fin de cooperar a con las autoridades e intensificar la educación cívica ${ }^{13}$.

En este contexto, la escuela chilena se estructuraba como una de las agencias dispuestas a generar la concientización nacionalista de la comunidad y persiguiendo cualquier atisbo de peruanidad en la zona (González 2004). Incluso, desde las escuelas se constituyeron las denominadas Ligas Patrióticas Infantiles que apoyaban la causa chilena, como la organizada en Tacna el 10 de septiembre de 1925. En aquel entonces se informaba al Intendente que:

El personal de profesores y alumnos de las escuelas Superior $\mathrm{N}^{\circ} 3$ y Elemental $\mathrm{N}^{\circ} 6$, hemos formado la "Liga Patriótica Infantil". Cuyo fin primordial será intensificar la campaña en pro de la causa Chile en el plebiscito que decidirá la soberanía de los territorios ${ }^{14}$.

Se considera así a la escuela como el agente que puede desarrollar una labor patriótica entre los estudiantes, como fuente de conocimiento de sus adscripciones y la de sus padres, concediéndole al Intendente la calidad de Presidente Honorario de dicha organización política.

Una vez acaecido el Tratado de Lima de 1929, el nacionalismo tomó un giro cultural que intensificó la recreación de una unidad simbólica nacional. Esta política estatal se realizó por intermedio de la escuela, y de manera más concreta por medio de la acción de los profesores normalistas, quienes se desplazaban a los más recónditos parajes del territorio nacional asimilando el diverso acervo cultural bajo una sola mirada: la chilena.

Desde entonces, la escuela he reproducido en gran medida un currículum educativo único que da cuenta de un Estado nacional unificado, mediante la enseñanza de asignaturas como historia y geografía y de humanidades en general, con un claro sesgo positivista decimonónico y un exacerbado nacionalismo. De manera especial, la Guerra del Pacífico 
pasó a ser el eje fundante de la diferenciación con otros colectivos de migrantes, de pueblos originarios y de afrodescendientes. El Estado se apoya así en la expansión de un sistema escolar igualitario capaz de esparcir una cultura uniforme. Este nacionalismo inventa una cultura desprovista de toda base étnica, unificando el imaginario de la nación, imponiendo lenguajes para reforzar su coherencia y movilidad interna, y lograr así asegurar la lealtad de los ciudadanos que compartirían una concepción similar del mundo impuesta por el Estado y transmitida por su sistema escolar.

De esta forma cambia la percepción que se tiene de los actores de la frontera, entre el semejante y el otro. Se trata más bien de compartir el sentimiento de ciertos valores o representaciones que forman la realidad subjetiva de la nación, siendo esta un producto artificial de la comunidad política bajo una hegemonía liberal.

Desde esta perspectiva, para comprender de mejor forma nuestro objeto de estudio, debemos dirigir nuestra atención hacia aquello que se niega a cambiar, lo que se quiere que permanezca, y lo que finalmente se hibridiza y desplaza en esta zona de trifrontera. Siguiendo esta senda, nos interesa mostrar hasta qué punto los elementos nacionalistas manifiestos en la documentación histórica están presentes aún en el escenario de las escuelas actuales.

Para ello, en la siguiente sección nos abocaremos a mostrar la presencia de este componente en la vida cotidiana escolar de estudiantes migrantes peruanos y bolivianos en la actualidad.

\section{Dilemas de la integración: diversidad, nacionalismo y discriminación}

\section{Diversidad e integración}

La diversidad sociocultural que históricamente ha caracterizado al actual norte de Chile ha generado una particular forma de chilenidad en la zona. La región ha vivido procesos de movilidad transnacional de larga data, lo que ha contribuido a que la sociedad ariqueña se haya constituido por la confluencia de diferentes culturas y nacionalidades. Aquí padres, abuelos, bisabuelos de gran parte de los estudiantes, que han nacido y se han criado en un territorio peruano, boliviano y chileno, han adquirido una nacionalidad que ha llegado a ser la nacionalidad chilena, aunque sus orígenes sean tan diversos como las historias de vida de sus habitantes.
La diversidad cultural presente en los establecimientos de la región de Arica y Parinacota, especialmente rurales, evidencia que la dicotomía hijos/as de inmigrantes y niños/as chilenos/as es imprecisa, o al menos poco operativa para la investigación, reflejando más bien nuestro desconocimiento inicial acerca de la formulación de la propuesta de investigación basada en estudios previos realizados en la capital del país. Luego de nuestro trabajo de campo en estos establecimientos, hemos podido apreciar ciertas prácticas culturales que permiten matizar esta distinción. Por ejemplo, en las escuelas de los valles, las voces de los estudiantes comprenden una mezcla de acentos provenientes de distintos lugares, la mayoría de los/as niños/as tiene ascendencia indígena diversa, nos cuentan ser hijos de madres o padres peruanos, bolivianos o chilenos, y la mayoría tiene tez morena.

En sus momentos de esparcimiento danzan tinku, huaynos, y otros ritmos propios de localidades de Perú, Bolivia y Chile, enmarcadas todas en la macrorregión centro sur andina; mientras que para la celebración de las fiestas patrias chilenas (18 de septiembre), la mayoría participa de números artísticos y bailan danzas de distintas zonas del país (chilote, cueca, tote), siempre que sean autorizados por sus padres. Sin querer agotar la descripción ni ser exhaustivos al respecto, queremos simplemente subrayar que la diversidad cultural es un fenómeno vivo en las aulas de la región.

En este contexto, en general los profesores señalan que existe integración de la diversidad cultural. Uno de los profesores de una de las escuelas rurales estudiadas, nos comentó:

Aquí la inclusión no es complicada como en la ciudad. Los profesores acá respetan todo el bagaje cultural que ellos traen y nosotros trabajamos también al dar a conocer esta cultura que ellos traen. Todas las actividades que se realizan aquí se hacen respetando su cultura. El sector Pampa Algodonal está muy identificado con esta cultura. No hay discriminación y ellos se sienten bien acogidos. El saber también que nosotros promovemos su cultura, los atrae (educador intercultural bilingüe, Escuela rural 1).

Si tomamos en cuenta las interacciones de los niños(as) con profesores en la sala de clase de la 
Escuela rural 1, nos encontramos además con los esfuerzos que realizan los profesores para lograr la integración de sus estudiantes al sistema escolar. Se trata de estrategias que, aunque no son reguladas desde el poder central, han sido instauradas a partir de las distintas realidades migratorias de los estudiantes y sus familias. Por ejemplo, y de manera más concreta, vimos que muchas de las familias de los niños/as que asisten a la Escuela rural 1 provienen de localidades rurales de Perú y Bolivia, y son hijos de padres transeúntes que permanecen en Chile por períodos que dependen de las cosechas del valle de Azapa o Lluta. Además, en muchos casos no cuentan con la residencia permanente en el país. Ante estas situaciones se generan acciones que reflejan el esfuerzo de los educadores por facilitar la adaptación de sus estudiantes.

En las zonas urbanas también hemos apreciado prácticas de integración. Cuando consideramos las experiencias de vida cotidiana de los estudiantes en la escuela, en una de las entrevistas grupales realizadas a estudiantes de $7^{\circ}$ año, una de ellas señaló que: "Hacen actividad de baile de otro país. Actividad de almuerzos típicos. Todo eso. Sí, para recordar. Para recordar a nuestros países y así no estar tan lejos de eso" (estudiante peruano, $7^{\circ}$ año, Escuela urbana 3). Al momento de preguntar por la relación con los pares, una estudiante señaló: "Mis compañeros siempre estaban ahí y me ayudaban en todo. Como yo era la única diferente ahí, la única que era de otro país. Era como que ellos siempre me ayudaban, yo no entendía ni lo que hablaban a veces. Me decían mira esto es así, y ahí comenzaba aprender (estudiante peruana, $7^{\circ}$ año, Escuela urbana 3).

Como señalábamos, muchas de las acciones de integración suelen surgir de manera espontánea, llegando a desarrollarse de manera mantenida en el tiempo solo en algunos establecimientos educativos. Esto se aprecia en un relato de un docente que es parte de un establecimiento urbano:

Aquí, como ha sido una escuela siempre inclusiva, antes de que se decretara ley (...) hace muchos años empezamos a trabajar con niños con origen boliviano y peruano, más peruano que boliviano, así que cuando se ingresaron a los niños ecuatorianos los niños colombianos, nosotros ya empezamos a trabajar más que nada, la parte de, de poder ser aceptado este tipo de niños. Al comienzo tuvimos problemas con los niños que eran de nativos de acá y que discriminaban un poco al niño que era de origen peruano, boliviano, incluso al niño que venía de, de la escuela de, de la sierra acá, había un tipo de inclinación, entonces creamos un eslogan donde, teníamos que ser aceptados todos como iguales, como hermanos y de ahí que empezamos como una de las primeras escuela que creó, formó parte de la Machaq mara (año nuevo aymara) fue esta, y empezó, hicimos la, la ceremonia en grande, y empezamos a cultivar ese tipo de hermandad es más este grupo que tengo atrás siempre viaja a Perú y Bolivia, entonces con mayor razón fuimos desarrollando aspectos que tengan que ver con la hermandad y fraternidad que tenga que ver con los pueblos originarios que están cerca de nosotros, que somos frontera, y eso fue un trabajo que, se fue haciendo por el primer director, se dio cuenta de la situación y, empezamos a hacer un trabajo primero a nivel de niños, después de apoderados y así con los profesores (docente, Escuela urbana 2).

\section{Nacionalismo y discriminación}

Nuestra experiencia cotidiana con niños y niñas que asisten a las escuelas y colegios con mayor concentración de hijos de inmigrantes de la ciudad de Arica, nos ha permitido apreciar también la presencia de elementos nacionalistas. Además, estos muchas veces vienen acompañados de la lógica asimilacionista que suele utilizar la escuela a la hora de abordar la inserción e integración de los estudiantes. Una orientadora de una escuela rural sostiene: "Nosotros hacemos que quieran nuestra patria, les hacemos querer nuestra bandera, y les integramos haciéndoles partícipe de las celebraciones de fiestas patrias" (orientadora, Escuela rural 3). Además, un director agregó enfático: "Aquí no hay extranjeros, este no es un tema para nosotros, aquí son todos iguales" (director, Colegio urbano 1). Respecto de las experiencias de vida cotidiana de los estudiantes, uno de ellos de origen peruano manifestó en una entrevista grupal que: 
Cuando es el día de la independencia, igual nosotros debemos vestirnos como se visten ellos. No nos dan la oportunidad de vestirnos como nosotros estamos acostumbrados allá (estudiante peruano, $7^{\circ}$ año básico, Colegio particular subvencionado urbano 4).

Se puede apreciar que las valoraciones al respecto varían según los distintos actores, las características de los estudiantes y la ubicación de los establecimientos educativos a los que pertenecen. En este escenario, también hemos constatado prácticas que diferencian el color de piel, género, origen étnico y nacional, siendo especialmente dirigidas a estudiantes de origen peruano, boliviano, y de otras nacionalidades latinoamericanas, e incluso entre estudiantes chilenos cuando estos son minoría en el establecimiento educativo. Esto da cuenta de una clara discriminación de tipo nacionalista y según origen étnico en los establecimientos educacionales.

Uno de los resultados más relevantes de nuestro análisis es que los estudiantes normalmente señalan haber experimentado situaciones donde se expresa el rechazo, la marginación e incluso la burla hacia sus compañeros de origen boliviano, peruano, ecuatoriano, colombiano y chileno indígenas. Cuando a los estudiantes de los establecimientos educativos del área urbana se les hizo la pregunta: ¿Qué tipo de bromas les han hecho cuando llegaron a la escuela?, la totalidad de los estudiantes de origen extranjero e hijos de inmigrantes con o sin nacionalidad chilena, señalaron haber vivido la experiencia de ser tratados por un compañero o compañera chileno con alguna de las siguientes expresiones: "negro, cholo, paisano, indio", a lo que muchas veces se le agregaba la expresión: "devuélvete a tu país" (entrevistas grupales, estudiantes de $7^{\circ}$ a $8^{\circ}$ año básico).

Sumado a esto, y como ya señalamos, encontramos que la discriminación también está dirigida hacia las minorías que no necesariamente son indígenas, extranjeros o hijos de extranjeros (en los valles en la zona rural, también se presentan situaciones de discriminación hacia niños y niñas chilenos provenientes del sur de Chile, en cursos en que la mayoría de los niños y niñas tienen un origen transnacional e indígena.

En las interacciones observadas en las salas de clases apreciamos que cuando los profesores presencian este tipo de interacciones discriminatorias, reaccionan llamando la atención de los estudiantes, pues son entendidas como faltas. En algunos casos realizan una sanción verbal al estudiante y entregan un mensaje referido al respeto a la diversidad cultural ante todo los estudiantes. No obstante, en el recreo, durante la realización de juegos y en la sala de clases cuando los estudiantes no están en presencia de un profesor, tienden a presentarse más tipo de situaciones, por lo que tienden a no ser sancionadas por el desconocimiento de los profesores. Esto permite la configuración de relaciones de poder que tienden a situar a los estudiantes en distintos niveles jerárquicos en el sistema escolar.

En las localidades rurales, los establecimientos han realizado esfuerzos para adaptarse a la realidad migratoria de las familias de los estudiantes, y han adaptado su currículum formal y oculto a ello. Por ejemplo, mediante el reforzamiento antes de cada evaluación y la entrega de útiles y alimentación, incluso para el caso de niños y niñas cuyos padres se encuentran en situación transeúnte. Asimismo, los docentes señalan que este tipo de establecimientos es mucho más integrador que las escuelas particulares o particulares subvencionadas, tanto en la zona rural como urbana. Un profesor jefe nos señaló su experiencia al respecto:

Una manera de sentirse más seguro y además que [los padres] tienen trabajo ahí cerca ¿Para qué lo van a traer para acá? Prefieren de repente escuelas municipales, y no escuelas subvencionadas, particulares, porque sí que ahí notan una diferenciación con respecto a que hay un, ¿cómo le llaman?, una discriminación mucho más severa con las que son subvencionadas particulares... pero eso se ve, fíjate. En la escuela, los mismos apoderados me han dicho que se da esa inclinación en las escuelas más particulares, es más, nosotros cuando han salido niños de acá de octavo, y se han querido ir, porque la situación social ha mejorado, hay niños que son de origen altiplánico, y sus padres me han dicho: 'profesor, quiero llevarme de la escuela a mi hijo al colegio [X particular pagado] o al [Y particular subvencionado]', y yo dije: piénselo bien, 'porque a veces hay problemas ahí por discriminación a los niños; 'no profesor, sino, no pasa na'. Después al mes viene llorando para acá, 'profesor 
dijo usted, no le, no le hice caso y yo por querer tener un mejor colegio'; pero yo le dije, le dije yo, al final las niñas repetían, han vuelto para acá, solamente han repetido por querer estar acá. ¿Entiende?, porque acá la acogieron, la aceptaron, otros niños que también vienen de baja autoestima, y vienen de colegios subvencionados particulares... muchos fíjate, muchos niños de [colegios] subvencionados particulares los han discriminado. Y yo dije: ¿pero, cómo?, si allá hay orientador, ¿cómo van a ser discriminados? Y ahí me cuentan la historia... (profesor jefe, Escuela urbana 2).

No obstante, en este contexto donde se deslizan elementos nacionalistas y la discriminación acecha constantemente las aulas, también existen actores conscientes de esta problemática y de posibles soluciones al respecto.

Saben que la presencia de diversidad cultural en los establecimientos de la región genera tensiones entre los diversos actores, pero que muchas de ellas están originadas en el simple desconocimiento de las realidades particulares que viven los niños y niñas que cada día se educan en la frontera norte del país. Al preguntarle cómo percibía la llegada de los niños/as hijos de inmigrantes al sistema escolar chileno, uno de los profesores nos señaló:

Hace falta sensibilizar creo yo, tanto como en las escuelas rurales, como en las escuelas de Arica, públicas, privadas, comunidad en general, sensibilizar e informar, porque hay mucha desinformación, y ... y el hecho de, de no tener conocimiento de algunos aspectos, eh hace que las personas cometan errores y que eh... discriminen a las personas. Por ejemplo, personas que ni conocen la cultura o no tienen idea, lo único que saben es que, por ejemplo, o la noción que tienen es que, lo, las personas que son de tez morena, son aymara, indígenas y por el hecho de ser indígena, son unos cholos son unos, son unos rateros, o unos labradores de tierra, que no hacen nada. O sea, yo me he topado con esa percepción de las personas. Así que, eh... eso más que nada, sensibilizar, educar, tanto como al, a los profesores, a los docentes (educador intercultural bilingüe, Escuela rural 1, entrevista semiestructurada).

\section{Consideraciones finales}

En este artículo hemos analizado la presencia de componentes nacionalistas desde una perspectiva histórica en las escuelas de la Región de Arica y Parinacota, y cómo estas se mantienen actualmente en la vida cotidiana escolar de niños y niñas hijos de inmigrantes peruanos y bolivianos. Nuestra evidencia nos permite afirmar que el proceso de integración de los estudiantes hijos/as de inmigrantes peruanos y bolivianos, entre otros, se suele realizar siguiendo una lógica de asimilación de los patrones culturales que entrega la escuela chilena. Debido a la herencia histórica de la chilenización y los subsecuentes procesos históricos que no han logrado eliminarla por completo, la escuela sigue reproduciendo los valores de una cultura chilena hegemónica y homogénea, donde la diversidad es tratada siempre como un aspecto marginal y que debe pasar por el cedazo de la incorporación cultural que realicen individualmente las minorías. En un escenario donde históricamente ha habido presencia y circulación de poblaciones andinas, tanto de Perú como de Bolivia y Chile, la creciente ola migratoria no ha hecho más que aumentar la diversidad cultural. No obstante, a causa de las limitaciones históricas, políticas y culturales que ha vivido la escuela, esta se ha transformado en uno de los ámbitos donde se reproducen prácticas de discriminación hacia estas minorías. Estas prácticas suelen manifestarse como actitudes, acciones y expectativas que no solo reproducen este ideario nacionalista, sino que además son en gran medida la base de sus manifestaciones específicas: la discriminación de tipo nacionalista, racial y étnica, las que muchas veces se presentan de forma conjunta y se potencian.

Al respecto, podemos concluir que si bien existen avances a nivel estatal y sobre todo esfuerzos que se realizan concretamente en los establecimientos educacionales de la región, estas iniciativas no son sistemáticas ni suficientes para afrontar el desafío de la integración de la diversidad cultural que viven las escuelas y colegios de la zona. En este artículo no solo hemos mostrado evidencia etnográfica actual acerca de esta problemática, sino también evidencia documental que dé cuenta de su profundidad y raíces históricas.

Solo considerando conjuntamente ambas evidencias, podremos estar en condiciones de imaginar nuevos lineamientos que le permitan a la política pública avanzar hacia procesos de integración 
cultural más íntegros y acordes con la realidad peculiar de la región. Así, podremos recoger uno de los requerimientos que los mismos docentes nos testimoniaron: sensibilizar y educar en y para la diversidad cultural.

\section{Agradecimientos}

Se agradece al Convenio Marco UTA1856. El tercer autor agradece a Becas Chile de CONICYT, $\mathrm{N}^{\mathrm{o}} 72150364$ (2014).

\section{Referencias Citadas}

Aguirre, C. y Mondaca, C.

2011 "Estado Nacional y Comunidad Andina. Disciplinamiento y Articulación Social en Arica, 1880-1929". Revista Historia, 44(1): 5-50.

Contreras, Yasna, Tapia, Marcela, y Liberona, Nannette

2017 Movilidades y prácticas socioespaciales fronterizas entre arica y tacna. Del sentido de frontera a la transfrontericidad entre ciudades. Diálogo Andino (54), 127-141. https://dx.doi. org/10.4067/S0719-26812017000300127

Dilla Alfonso, Haroldo, y Álvarez Torres, Camila

2018 "Arica/Tacna: los circuitos económicos de un complejo urbano transfronterizo". Diálogo Andino (57), 99-109. https://dx.doi.org/10.4067/S0719-26812018000300099

Guizardi, M.

2014 "Migración, integración y nacionalismo: Reflexiones para una ciudadanía inclusiva". Revista Migraciones, 35 : 43-70.

Guizardi, M. y Garcés, A.

2013 "Circuitos migrantes: Itinerarios y formación de redes migratorias entre Perú, Bolivia, Chile y Argentina en el norte grande chileno". Revista Papeles de Población, 78(19): 65-110.

Joiko, S. y Vásquez, A.

2016 "Acceso y elección escolar de familias migrantes en Chile: No tuve problemas porque la escuela es abierta, porque acepta muchas nacionalidades". Revista Calidad en la Educación, 45, 132-173.

Mardones, $\mathrm{P}$.

2006 Exclusión y sobreconcentración de la población escolar migrante bajo un modelo de segregación socioterritorial. Buenos Aires: CLACSO.

Mondaca, C., Rivera, P. y Aguirre, C.

2013 "La escuela y la guerra del Pacífico: Propuesta didáctica de historia para la inclusión educativa en contextos transfronterizos del norte de Chile". Revista Si Somos Americanos, 13(1): 123-148.

Mondaca, C. y Gajardo, Y.

2013 "La educación intercultural bilingüe en la región de Arica y Parinacota, 1980-2010". Revista Diálogo Andino, 42: 68-87.

Mondaca, C., Gajardo, Y. y Sánchez, Elizabeth

2014 "Historia, memoria y ciudadanía intercultural: El reto del siglo XXI para las aulas de la región de Arica y Parinacota, norte de Chile". Revista Interciencia, 39(7): 524-530.

Mondaca, Carlos

2018 Educación y migración transfronteriza en el norte de Chile: procesos de inclusión y exclusión de estudiantes migrantes peruanos y bolivianos en las escuelas de la región de Arica y Parinacota. Tesis para optar al grado de Doctor en Educación. Universidad Autónoma de Barcelona.
Pavez Soto, Iskra, y Galaz Valderrama, Caterine

2018 "Hijas e hijos de migrantes en Chile: Derechos desde una perspectiva de inclusión social". Diálogo Andino (57), 73-86. https://dx.doi.org/10.4067/S0719-26812018000300073

Poblete, R.

2009 "Educación intercultural en la escuela de hoy: Reformas y desafíos para su implementación". Revista Latinoamericana de Educación Inclusiva, 3(2): 181-200.

Rojas, N. y Vicuña, J. (Eds.)

2014 Migración y Trabajo. Estudio y propuestas para la inclusión sociolaboral de migrantes en Arica. Santiago: Ciudadano Global - Servicio Jesuita Migrantes.

Stefoni, C.

2003 Inmigración peruana en Chile: Una oportunidad a la integración. Santiago: Editorial Universitaria.

Stefoni, C.

2004 Inmigración y ciudadanía: La formulación de comunidades peruanas en Santiago y la emergencia de nuevos ciudadanos. Santiago: Universidad de Chile.

Tapia, M. y González, A.

2014 Regiones Fronterizas. Migración y los desafíos para los Estados nacionales latinoamericanos. Santiago: RIL Editores - Universidad Arturo Prat.

Tijoux, M.

2013 "Niños (as) marcados por la inmigración peruana: Estigma, sufrimientos, resistencias". Revista Convergencia, $\mathrm{N}^{\circ}$ 61: 83-104.

Vicuña, J. y Rojas, T.

2015 Migración en Arica y Parinacota. Panoramas y tendencias de una región Fronteriza. Santiago: Servicio Jesuita a Migrantes - Universidad Alberto Hurtado.

Zapata Sepulveda, Pamela; Tijoux Merino, Maria Emilia y Espinoza Lobos, Michelle

2015 "La investigación crítica como una forma de romper el cristal entre las prácticas comunes en la academia publica chilena y el caso de los estudiantes migrantes latinoamericanos de color en nuestras salas de clases: un llamado a humanizar, un llamado a reflexionar". Diálogo Andino (47), 71-81. https://dx.doi.org/10.4067/S0719-26812015000200008

\section{Fuentes documentales}

Archivo Histórico Vicente Dagnino. Biblioteca Universidad de Tarapacá. Arica-Chile.

- Fondo: Decretos, Intendencia de Tacna.

- Fondo Subdelegación de Putre.

- Fondo: Copiador de Notas de la Intendencia, 1899.

- Fondo: Legajo Subdelegados 1905-1906.

- Fondo Comunicaciones Recibidas, 1916-1920 (cartas).

- Fondo Oficios diversos recibidos 1920-1923, 1925. 


\section{Notas}

1 Esto se aprecia en la promoción e imposición de elementos como el rodeo, danzas como la cueca y las bandas musicales militares.

2 Archivo Histórico Vicente Dagnino (en adelante AHVD), Decretos, Intendencia de Tacna. Vol. 18, foja 7, 1892.

3 AHVD, Copiador de Notas de la Intendencia, 1899, Folio s/dato. N ${ }^{\circ}$ Ficha 46-47.

4 AHVD, Decretos de la Intendencia de Tacna, 1901, Folio s/dato. Vol. 105, No Ficha 34.

5 AHVD, Decretos de la Intendencia de Tacna, 1901, Folio s/dato. Vol. 105, Nº Ficha 34.

6 AHVD, Decretos de la Intendencia de Tacna, 1901, Folio s/dato. Vol. 105, N ${ }^{\circ}$ Ficha 34.

7 AHVD, Decretos de la Intendencia de Tacna; Incluye información FFCC. Arica-La Paz, 1915. Vol.129. Nº Ficha 117. Tacna, 18 de noviembre de $1915 . \mathrm{N}^{\circ} 118$.

8 AHVD, Legajo Subdelegados 1905-1906. Carta rotulada con los números 24 al 27.

9 AHVD, Carta, 1916, Vol. 157, Nº Ficha 65.
10 AHVD, Carta, 1920, Vol. 164, N Ficha 261.

11 AHVD, Oficios diversos recibidos; Incluye: resguardo de fronteras, Educación, Liceos, Estadísticas, escuelas públicas, 1920. Vol. 61. N Ficha 199. Folio 103. Tacna, 27 de agosto de 1920.

12 AHVD, Oficios Recibidos por la Intendencia remitidos por varios; incluye: Liceo de Hombres, Liceo de Niñas, Visitación de las Escuelas, Instituto Comercial, Oficina de la Vacuna, Beneficencia, Hospital, Casa de Orates, 1923, Vol. 71 folio 162, número 117. Tacna, 9 de octubre de 1923.

13 AHVD, Oficios recibidos por la Intendencia remitidos por varios; incluye: Liceo de Hombres, Liceo de Niñas, Visitación de las Escuelas, Instituto Comercial, Oficina de la Vacuna, Beneficencia, Hospital, Casa de Orates. 1923. Vol.71. Folio $180, \mathrm{~N}^{\circ}$ Ficha 151. Tacna, 13 de noviembre de 1923.

14 AHVD, Oficios recibidos por la Intendencia remitidos de varios, 1925, vol. 77, folio $122,1925$. 